\title{
Descrição de duas espécies novas de Agudus Oman (Homoptera, Cicadellidae, Deltocephalinae) ${ }^{1}$
}

\section{Keti Maria Rocha Zanol ${ }^{2}$}

\begin{abstract}
Descriptions of two new species of Agudus Oman (Homoptera, Cicadellidae, Deltocephalinae). Two new species of Agudus Oman are described: $A$. miriamae sp.n. and A. pillosus sp.n., both from Brazil.

KEY WORDS. Agudus, Cicadellidae, Deltocephalinae, Homoptera.
\end{abstract}

O gênero Agudus foi descrito por OMAN (1936) para abrigar a espécie $A$. typicus. LINNAVUORI (1959), descreveu A. sexmaculatus e A. superbus e transferiu para este gênero Platymetopius longiceps Berg, 1879. DELONG \& LINNAVUORI (1978) descreveram A. strigilifer e A. amabilis. CHENG (1980) descreveu quatro espécies: A. lepidus, A. cyrtobrachium, A. forficatus e A. blockeri. Descreve-se duas novas espécies: A. miriamae sp.n. e A. pillosus sp.n., ambas para o Brasil.

O material estudado pertence as seguintes Instituições: DZUP - Coleção de Entomologia Pe J.S. Moure, Curitiba; BMNH - The Natural History Museum, Londres.

\section{Agudus miriamae sp.n.}

Figs 1-10

Holótipo macho. Coloração geral amarelo-dourado. Coroa com uma faixa longitudinal que se estende desde o ápice até a sutura coronal e duas, uma de cada lado da sutura amarelo-pálidas. Margem anterior com arcos marrons. Face marromclara com arcos laterais amarelo-pálidos. Pronoto com seis faixas longitudinais, amareladas. Tégminas transparentes com uma pequena mancha marrom na célula anteapical internal, segunda célula discal e sobre a veia extranumerária do clavo.

Cabeça mais larga que o pronoto. Coroa cerca de 2,5 vezes mais longa no meio do que junto aos olhos. Sutura coronal atingindo a metade do comprimento da coroa. Ocelos, na margem anterior, visíveis de cima. Área ocelo-ocular igual ao diâmetro dos ocelos. Anteclípeo mais estreito na base, túmido. Genas sinuosas com reentrância abaixo dos olhos.

Pronoto com leves estrias transversas. Tégminas com três células anteapicais fechadas. Apêndice curto. Clavo com uma veia extranumerária entre $1 \mathrm{~A}$ e a sutura claval.

1) Contribuição número 1079 do Departamento de Zoologia, Universidade Federal do Paraná.

2) Departamento do Zoologia, Universidade Federal do Paraná. Caixa Postal 19020, 81531-990 Curitiba, Paraná, Brasil. Bolsista do CNPq. 


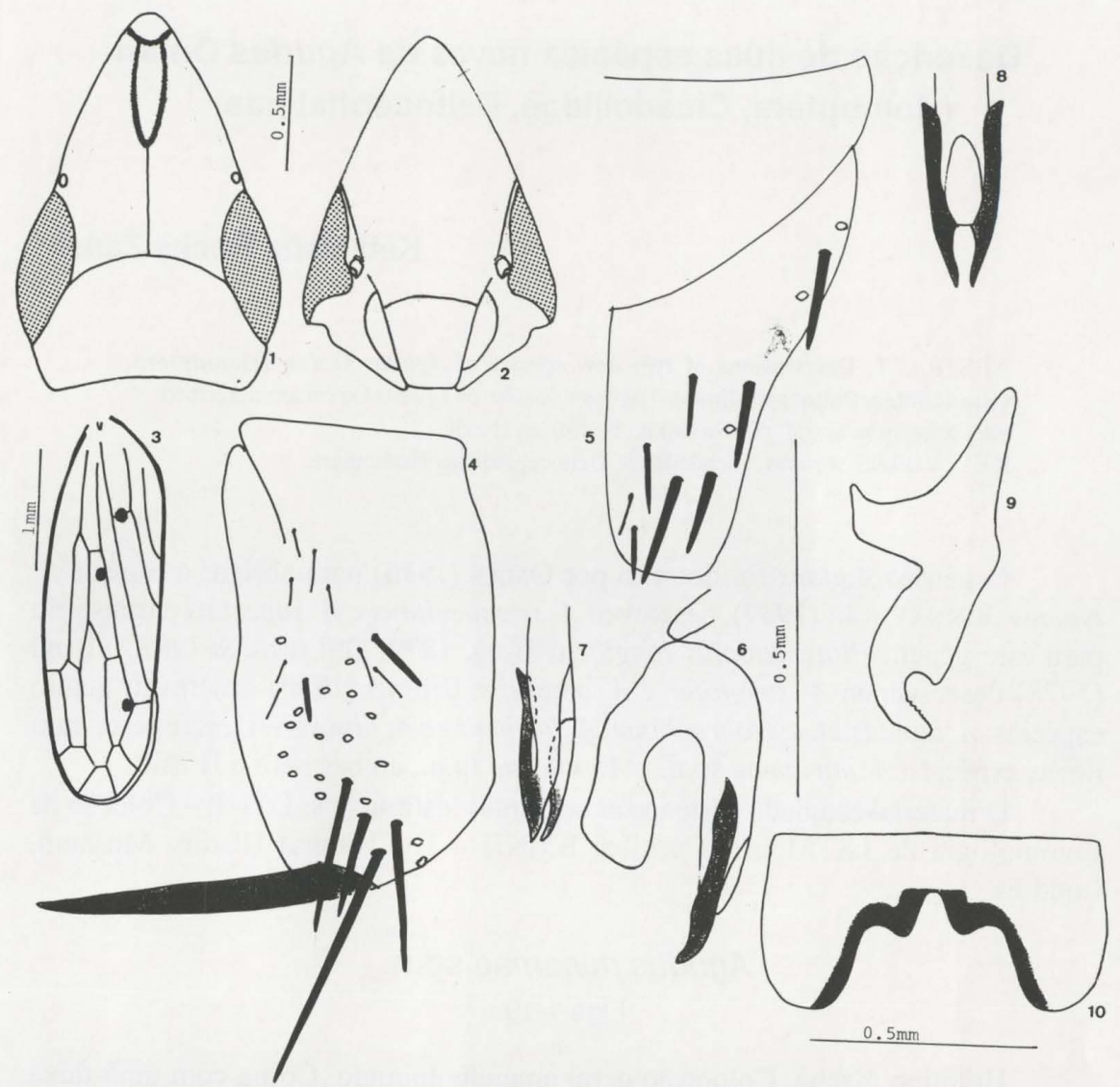

Figs 1-10. Agudus miriamae sp.n.. (1) Cabeça e pronoto, dorsal; (2) face; (3) tégmina; (4) pigóforo, lateral; (5) valva e placa subgenital; (6) edeago, lateral; (7) apêndices do edeago, látero-ventral; (8) apêndices do edeago, ventral; (9) estilo; (10) sétimo esternito, fêmea.

Pigóforo com ápice truncado; um par de apêndices, paralelos, direcionados para baixo. Placas subgenitais com as margens sinuosas e ápice truncado; superfície interna com um processo esclerotinizado, na altura do ápice dos estilos; macrocerdas dispersas. Edeago mais ou menos robusto com um par de apêndices apicais, laterais, paralelos ao edeago, com as extremidades afiladas e divergentes. Gonóporo apical, na superfície ventral.

Fêmea. Sétimo esternito com margem posterior emarginada e bilobada com uma fenda mediana em forma de $\mathrm{U}$ invertido.

Comprimento total. Macho: 4,70mm, fêmea: $5,00 \mathrm{~mm}$.

Material examinado. Holótipo macho, BRASIL, Goiás: Jataí, XI.1971/ F.M. Oliveira leg. B.M. 1972-541 (BMNH). Parátipos. BRAsIL, Mato Grosso: Jacaré (Xingú), XI.1961, M. Alvarenga leg., B.M. 1976-232, 2 fêmeas (BMNH, DZUP). 
Comentário. Esta espécie, aparentemente, aproxima-se de A. cyrtobrachium pela presença de apêndices no pigóforo e edeago.

Espécie dedicada à Professora Dra Miriam Becker, Universidade Federal do Rio Grande do Sul, estudiosa da ecologia dos Heteroptera e Homoptera.
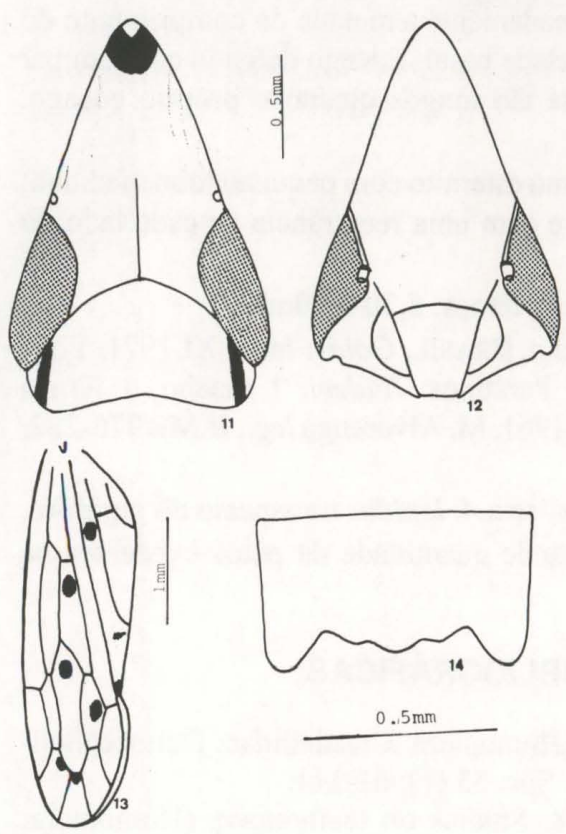

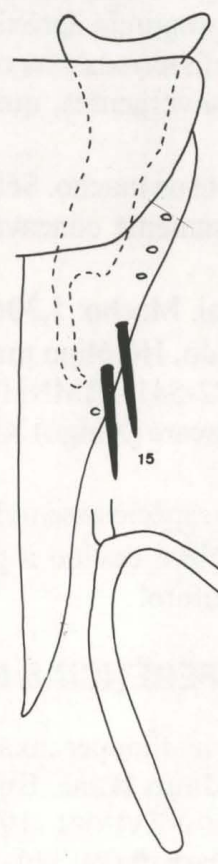

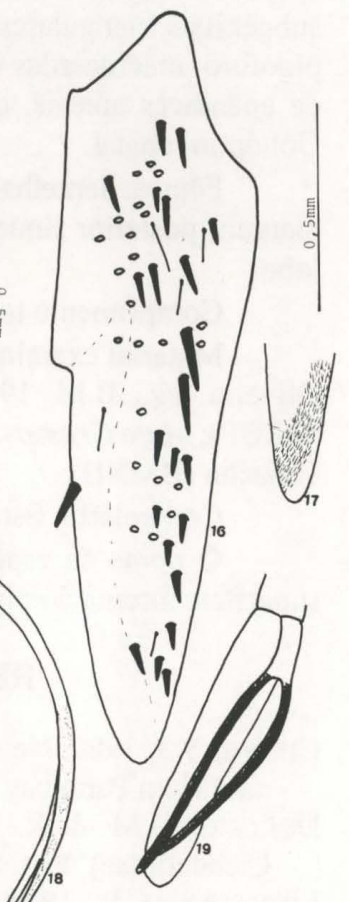

Figs 11-19. Agudus pillosus sp.n.. (11) Cabeça e pronoto, dorsal; (12) face; (13) tégmina; (14) sétimo esternito, fêmea; (15) valva, placa subgenital e estilo; (16) pigóforo, lateral; (17) ápice do pigóforo, interno; (18) edeago, lateral; (19) edeago, látero-ventral.

\section{Agudus pillosus sp.n.}

Figs 11-19

Holótipo macho. Semelhante a espécie precedente porém a sutura coronal não atinge a metade da coroa.

Coloração geral marrom-dourada; margem anterior com arcos marrom-claros; ápice marrom-escuro com uma área mais ou menos triangular esbranquiçada. Coroa com uma faixa longitudinal que se estende desde a mancha marrom-escura até a sutura coronal e uma de cada lado dessa sutura, esbranquiçadas. Frontoclípeo marrom-claro com arcos laterais amarelados. Pronoto com uma faixa longitudinal, lateral, marrom e seis faixas amareladas. Tégminas semitransparentes, marrom-douradas com sete manchas arredondada marrom-escuras: na veia extranumerária entre 
1A e a sutura claval, na segunda célula discal, nas células anteapicais central e interna, na segunda e terceira células apicais e no ápice do clavo. Venação esbranquiçada.

Pigóforo muito longo e estreito, de forma mais ou menos cônica, sem apêndices; superfície interna com um tufo de pêlos escuros, próximo ao ápice. Placas subgenitais triangulares atingindo aproximadamente a metade do comprimento do pigóforo; macrocerdas unisseriadas, na metade basal. Edeago delgado com um par de apêndices apicais, convergentes, quase tão longos quanto o próprio edeago. Gonóporo apical.

Fêmea. Semelhante ao macho. Sétimo esternito com pequeno lobo mediano; margem posterior sinuosamente côncava e com uma reentrância de cada lado do lobo.

Comprimento total. Macho: 5,30mm, fêmea: 5,30-5,70mm.

Material examinado. Holótipo macho, BRASIL, Goiás: Jataí, XI.1971/ F.M. Oliveira leg., B.M. 1972-541 (BMNH). Parátipos: Ibidem, 1 macho, 1 fêmea (DZUP); Mato Grosso: Jacaré (Xingú) XI.1961, M. Alvarenga leg., B.M.1976-232, 1 macho (BMNH).

Comentário. Esta espécie assemelha-se a A. lepidus no aspecto do pigóforo.

O nome da espécie é devido a grande quantidade de pêlos existentes na superfície interna do pigóforo.

\section{REFERÊNCIAS BIBLIOGRÁFICAS}

CHENG, Y.J. 1980. New leafhopper taxa (Homoptera: Cicadellidae: Deltocephalinae) from Paraguay. Jour. Kans. Ent. Soc. 53 (1): 61-111.

DELonG, D.M. \& R. LinNAVUoRI. 1978. Studies on leafhoppers (Homoptera: Cicadellidae). Ent. Scan. 9 (2): 111-123.

LINNAVUORI, R. 1959. Revision of the Neotropical Deltocephalinae and some related subfamilies (Homoptera). Ann. Zool. Soc. Vanamo 20 (1): 1-370.

OMAN, P. 1936. A generic revision of American Bythoscopinae and South American Jassinae. Univ. Kans. Sci. Bull. 24 (16): 343-420.

Recebido em 20.VIII.1998; aceito em 31.V.1999. 